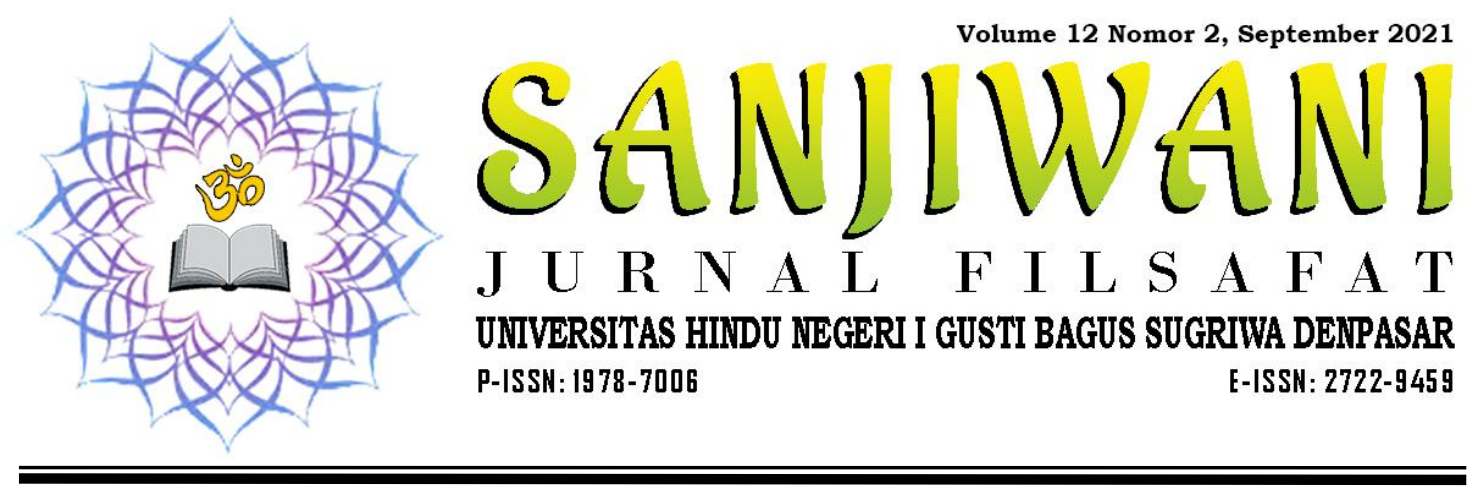

\title{
Agama Hindu di Indonesia: Perumusan Konsep Keberagamaan Hindu dalam Kehidupan Berbangsa dan Bernegara
}

Putu Eka Sura Adnyana', Ni Nyoman Suryani ${ }^{2}$

DPP Peradah Indonesia Bali1, SMPN 2 Kabupaten Gianyar ${ }^{2}$ ekasuraadnyana@gmail.com ${ }^{1}$, suryaninyoman@gmail.com ${ }^{2}$

\begin{tabular}{|c|c|}
\hline Keywords: & ABSTRACT \\
\hline $\begin{array}{l}\text { Indonesian } \\
\text { Hinduism; Hindu } \\
\text { Religious } \\
\text { Concepts; Hindu } \\
\text { History }\end{array}$ & $\begin{array}{l}\text { Indian culture has a lot of influence on the religious and social } \\
\text { activities of the Hindu community in the archipelago. One of them } \\
\text { is the use of animals in the religious social activities of the Hindu } \\
\text { community in the archipelago. The similarity of the concept of } \\
\text { Vedic teachings and their implementation in the Land of the } \\
\text { Archipelago encouraged the ancestors to fight for Hinduism to be } \\
\text { recognized in Indonesia. This paper aims to describe and explain } \\
\text { the journey of the formulation of Hinduism in Indonesia. This } \\
\text { paper is expected to be useful for the wider community, especially } \\
\text { the Hindu community. This paper uses the method of collecting } \\
\text { data through observation, with a combination of listening and note- } \\
\text { taking methods, as well as data analysis using qualitative } \\
\text { descriptive analysis techniques and methods of presenting results } \\
\text { with non-formal techniques. The syncretism of Vedic teachings and } \\
\text { ancestral teachings has occurred for centuries, both from the } 5 \\
\text { theories of the entry of Hinduism to Indonesia, from the process of } \\
\text { the Indians traveling to the archipelago known as the Bali Yatra, } \\
\text { and from the mangjawaken byasa mata process carried out by the } \\
\text { king of Kediri, namely Dharma Wangsa. Firm in the 9th century } \\
\text { AD. The recognition of Hinduism in Indonesia encouraged Hindu } \\
\text { intellectuals at that time to immediately formulate Hindu religious } \\
\text { concepts for the life of the nation and state, such as the name of the } \\
\text { highest entity, the concept of carrying out daily prayers, holy days, } \\
\text { organizations, and so on. This indicates the importance of } \\
\text { understanding the Hindu red coat in Indonesia. }\end{array}$ \\
\hline
\end{tabular}

\begin{tabular}{|lc|}
\hline Kata Kunci & ABSTRAK \\
\hline $\begin{array}{l}\text { Agama Hindu } \\
\text { Indonesia; }\end{array}$ & Kebudayaan India banyak memberikan pengaruh \\
terhadap aktivitas sosial religius keberagamaan masyarakat
\end{tabular}




\begin{tabular}{|ll}
\hline Konsep & Hindu di Nusantara. Salah satunya adalah penggunaan \\
Keberagamaan & hewan dalam aktivitas sosial religius masyarakat Hindu di \\
Hindu Sejarah & Nusantara. Kesamaan konsep ajaran Veda dan \\
& pengimplementasiannya di Tanah Nusantara mendorong \\
& para leluhur dahulu berjuang untuk Hindu di akui di \\
& Indonesia. Tulisan ini bertujuan mendeskripsikan dan \\
& menjelaskan perjalanan perumusan agama Hindu di \\
& Indonesia. Tulisan ini diharapkan dapat bermanfaat kepada \\
& masyarakat luas terutamanya masyarakat Hindu. Tulisan ini \\
& menggunakan metode pengumpulan data melalui observasi, \\
& dengan kombinasi metode simak dan teknik catat, serta \\
& analisis data menggunakan teknik analisis deskriptif \\
& kualitatif dan metode penyajian hasil dengan teknik non \\
& formal. Sinkritisme ajaran Veda dan ajaran leluhur telah \\
& terjadi berabad-abad lamanya, baik dari 5 teori masuknya \\
& agama Hindu ke Indonesia, dari proses perjalanan orang \\
& India ke Nusantara yang dikenal dengan Bali Yatra, serta dari \\
& proses mangjawaken byasa mata yang dilakukan oleh raja \\
& Kediri yaitu Dharma Wangsa Teguh pada abad ke-9 masehi. \\
& Pengakuan Hindu di Indonesia memberi semangat para \\
& intelektual Hindu pada masa itu untuk segera merumuskan \\
konsep keberagamaan Hindu bagi kehidupan berbangsa dan & bernegara, seperti nama entitas tertinggi, konsep \\
pelaksanaan doa sehari-hari, hari suci, organisasi dan lain & sebagainya. \\
&
\end{tabular}

\section{PENDAHULUAN}

Jas merah demikianlah yang pernah disampaikan Bung Karno dalam pidatonya sebagai Presiden RI pertama kepada seluruh masyarakat Indonesia. Jas merah merupakan akronim dari Jangan sekali melupakan sejarah, pesan yang wajib diingat dan dipahami oleh generasi muda. Salah satunya bagi generasi muda Hindu untuk memahahi Jas Merah agama Hindu di Indonesia yang tidak terlepas dari kebudayaan India. Kebudayaan India banyak memberikan pengaruh terhadap aktivitas sosial religius keberagamaan masyarakat Hindu di Nusantara.

Salah satunya adalah penggunaan hewan dalam aktivitas sosial religius masyarakat Hindu di Nusantara. Hewan menjadi hal penting dalam pelaksanaan kegiatan upacara yajna di Nusantara, dan terkhususnya di Bali. Jika Merujuk pada Rg Veda I.162.11 dengan jelas dinyatakan "apa yang menetes dari daging yang sedang diguling diatas panggangan, jangan dibiarkan ada tercecer di tanah atau rumput, haturkan semua kepada dewa" (Pudja, 1979:332). Kutipan mantram Rg Veda I.162.11 tersebut menjelaskan bagaimana penggunaan hewan dalam penggunaan yajna. Pembumian mantram Veda tersebut dapat dilihat pada pelaksanaan Upacara Mapepada. Upacara Mapepada adalah upacara penyucian binatang-binatang kurban serta mendoakan agar roh-roh itu agar menjelma menjadi mahluk lebih tinggi derajatnya kelak bahkan didoakan 
menjadi manusia utama. Upacara ini dilaksanakan sebelum hewan-hewan itu dipotong untuk pelaksanaan yajna.

Kesamaan konsep ajaran Veda dan pengimplementasiannya di Tanah Nusantara mendorong para leluhur dahulu berjuang untuk Hindu di akui di Indonesia. Jika mengingat sejarah Indonesia dari abad I-XV kerajaan di Nusantara bercorak Hindu (Soekmono dalam Adnyana, 2020). Kerajaan Hindu yang sangat terkenal saat itu tercatat dalam sejarah Indonesia adalah kerajaan Majapahit dengan raja bernama Hayam Muruk dan Mahapatih Gajah Mada. Runtuhnya majapahit abad ke XV akhir, ditambah dengan proses islamisasi ditanah jawa dan kolonialisasi dari penjajah Belanda dan Jepang telah banyak menghilangkan kebudayaan Veda dan peninggalan Hindu di Nusantara, namun sebagian ada juga yang direkontruksi kembali (Adnyana, 2020). Dalam perjalanan kemerdekaan Indonesia, ajaran agama Hindu banyak memberikan kontribusi untuk negara Indonesia. Beberapa diantaranya nama dasar negara Indonesia yaitu pancasila, dengan ciri khas burung garuda yang bermakna burung pembebasan (baca: teks Adiparwa dalam cerita Sang Garuda) dan semboyan persatuan dan kesatuan negara Indonesia yaitu Bhinneka Tunggal Ika "Berbeda-beda tetapi tetap satu jua" yang bersumber pada kakawin sutasoma, dan masih banyak yang lainnya.

Hal itu semua mendorong para leluhur terdahulu, yang tergabung dalam para intelektual Hindu dan rohaniawan Hindu pasa masa itu, berjuang untuk mendapatkan pengakuan dari Negara Indonesia. Pengakuan agama Hindu diawali dari gagasan intelektual Hindu di pulau Bali dengan penuh jalan likaliku, suka dan duka perjuangan hingga Hindu berhasil tercatat dalam ketatanegaraan Indonesia sebagai salah satu agama di Indonesia. Salah satu tokoh perjuangan tersebut adalah I Gusti Bagus Sugriwa. Yang kini nama beliau diabadikan dalam nama Universitas Hindu Negeri I Gusti Bagus Sugriwa Denpasar. Oleh karena itu tulisan ilmiah ini mencoba untuk membahas pertemuan ajaran leluhur dan ajaran Veda, jas merah perjuangan Agama Hindu di Indonesia, dan perumusan konsep keberagamaan Hindu dalam kehidupan berbangsa dan bernegara.Tentunya tujuan dan manfaat dapat memberikan sumbangsih pengetahuan bagi masyarakat luas, terutamanya bagi generasi muda agar menumbuhkembangkan rasa cinta terhadap agama Hindu "Proud to be Hindu".

\section{PEMBAHASAN}

\subsection{Pertemuan Sinkritisme Ajaran Veda dan Ajaran Leluhur}

Ajaran Veda berasal dari India. Di India banyak melahirkan dan mewariskan tradisi intelektual dan spiritual. Hindu diawali peradaban lembah sungai Sindhu yang pra Veda yang merupakan cikal bakal agama Hindu yang sudah bersintesa dengan zaman Veda yang dibangun oleh bangsa Arya yang datang ke India jauh sebelum tarikh masehi. Pemujaan kepada dewi atau sakti, dan dewa-dewa dalam bentuk pasupati dan praktek yoga merupakan cikal bakal berkembangnya agama Siwa (Phalgunadi, 2010). Phalgunadi (2010) menjelaskan setelah masuknya bangsa Arya pemujaan Siwa dalam bentuk Rudra tercantum dalam kitab suci Veda bagian Satrudriya, sehingga proses evolusi berpikir tataran 
metafisika, etika dan agama Weda (Vedic Religion) terus berkembang menjadi fase-fase dengan ciri dan karakter tersendiri sebagai jawaban para intelektual India Kuna terhadap perkembangan dan tuntutan zaman.

Perkembangan Veda telah banyak mengalami evolusi terjadinya bentukanbentuk baru seperti saiwa agama, waisnawa agama, sakta agama, dan smarta agama terhadap kehidupan agama, sosial dan kebudayaan India sehingga wajah dan praktek agama Hindu pada fase-fase tersebut nampak berbeda. Salah satunya yang dapat dijumpai pada pertemuan ajaran Veda dengan ajaran leluhur di Nusantara. Di Nusantara telah berkembang sistem kepercayaan pemujaan terhadap roh nenek moyang. Kepercayaan itu bersifat animisme dan dinamisme. Animisme merupakan satu kepercayaan terhadap roh atau jiwa sedangkan dinamisme merupakan satu kepercayaan bahwa setiap benda memiliki kekuatan gaib (Soekmono dalam Adnyana, 2020). Melalui masuknya kebudayaan India terutama sistem religi agama Hindu Buddha ke Nusantara khususnya kepada masyarakat Jawa Kuno kepercayaan yang dianut sebelumnya yaitu animisme dan dinamisme mengalami perpaduan dengan ajaran agama Hindu Buddha atau dengan kata lain mengalami proses sinkritisme (Adnyana, 2020). Sinkritisme adalah bagian dari proses akulturasi yang merupakan perpaduan dua kepercayaan yang berbeda menjadi satu kesatuan. Perpaduan ajaran tersebutlah yang menyebabkan perbedaan ajaran agama Hindu Buddha di Nusantara (Indonesia) dengan agama Hindu Buddha yang dianut oleh masyarakat India. Ada beberapa teori yang dikemukan oleh para ahli masuknya ajaran agama Hindu diantaranya, sebagai berikut.

1.) Teori Brahmana oleh JC. Van Leur. Teori ini didasari oleh pengamatan terhadap prasasti-prasasti peninggalan kerajaan Hindu-Buddha yang kebanyakan menggunakan literasi huruf pallawa dan bahasa Sanskerta. Di India, literasi tersebut hanya dikuasai oleh golongan Brahmana.

2.) Teori Waisya oleh N.J Krom. Teori ini menyatakan bahwa berkat peran serta golongan Waisya (pedagang) yang merupakan golongan terbesar masyarakat India yang berinteraksi dengan masyarakat Nusantara.

3.) Teori Ksatria oleh C.C Berg, Mookerji, dan J.C Moens. Teori ini menyatakan golongan bangsawan atau ksatria dari India yang membawa masuk dan menyebarkan agama Hindu ke Indonesia.

4.) Teori Sudra oleh Van Faber. Teori ini menyatakan bahwa diawali oleh para kaum sudra yang berimigrasi ke wilayah Nusantara

5.) Teori Arus Balik oleh F.D.K Bosch. Teori ini menyatakan peran aktif masyarakat Indonesia dimasa silam yang menimba ilmu ke India. Sekembalinya dari India, mereka kemudian menyebarkan pengetahuan mereka ke masyarakat yang lain. (Tarunasena, 2009:2)

Lima teori yang diformulasikan oleh para ahli sangat berkaitan dengan pengaruh India ke Nusantara beserta dengan sistem religi agama Hindu dan kehidupan masyarakat Jawa Kuno pada masa itu. Selain itu, dalam peninggalan arkelogis dinyatakan bahwa Rsi Agastya menyebarkan agama Hindu dari India 
ke Asia Tenggara hingga ke Indonesia (Poerbatjaraka; Rema; dalam Adnyana, 2020).

Nama Rsi Agastya ditemukan dalam beberapa prasasti, diantaranya, sebagai berikut.

a. Prasasti Dinoyo (Jawa Timur) bertahun saka 682, dimana seorang raja yang bernama "Gajahmana" membuat pura suci untuk Rsi Agastya dengan tujuan memohon kekuatan suci dari beliau.

b. Prasasti Porong (Jawa Timur) yang berangka tahun saka 785, juga menyebutkan keagungan serta kemulyaan Rsi Agastya. Mengingat kemulyaan Rsi Agastya, maka banyak istilah/sebutan yang diberikan kepada beliau, diantaranya adalah ; Agastya Yatra artinya perjalanan suci Rsi Agastya yang tidak mengenal kembali dalam pengabdiannya untuk dharma. Putra Segara artinya bapak dari lautan, karena beliau mengarungi berbagai lautan luas demi dharma (Rema, dalam Adnyana, 2020)

Perjalanan Agastya hingga ke Nusantara dengan menganut paham siwaisme dijelaskan oleh Poerbatjaraka (dalam Adnyana, 2020) terdapat juga dalam literature kesusatraan Jawa Kuno seperti pada kakawin Ramayana, kakawin Hariwangsa, kakawin Smaradhana, dan kakawin Tantu Pagelaran. Peran penting Rsi Agastya dalam menyebarkan ajaran Agama Hindu di Nusantara sangat berkaitan erat dengan paham siwaistik atau siwaisme dalam ajarannya, sebagaimana paham siwaisme yang dianut oleh Rsi Agastya dalam menyebarkan agama Hindu dari India ke Nusantara. Keterkaitan ajaran Rsi Agastya dengan paham siwaistik membuat para pengawi atau pujangga dalam membuat kesusatraan Jawa Kuno akan berlandaskan paham siwaistik tersebut.

Selain itu, ada perjalanan Bali yatra atau festival ituj uga dikenal sebagai Boita Bandana Utsawa "festival pemujaan perahu yaitu upacara pengiriman kapal ke pantai yang jauh". Festifal tersebut dilakukan di setiap rumah tangga pada daerah Odisha India, untuk mengenang Sadhabapuas (pedagang Odisha) yang telah memulai perjalanan bahari laut ke Bali, Jawa \& Sumatra untuk ekspansi perdagangan dan budaya serta melalukan hubungan bilateral lainnya dengan kerajaan - kerajaan di Nusantara yang dilaksanakan pada Kartika Purnima "hari bulan purnama dari bulan Kartika" (sekitar bulan Oktober - November) sesuai dengan kalender Hindu (Sanyal, dalam Adnyana, 2020).

Orang-orang India selatan yang menganut paham siwaistik (siwaisme) dalam ajaran agama Hindu melakukan yatra "perjalanan" ke Bali pada abad 2 SM juga dikenal dengan istilah Voyage to Bali "pelayaran menuju Bali" yang diperingati festival tersebut setiap tahunnya. Sanyal (dalam Adnyana, 2020) dalam bukunya "The Ocean of Churn: How the Indian Ocean Shaped Human History" menjelaskan perisitiwa ini terjadi sekitar akhir tahun 200 sebelum masehi. Pelaut pelaut India memulai pelayaran atau perjalanan dari Sungai Mahanadi. Sungai Mahanadi adalah sungai yang sangat penting dan aman yang mempunyai celah kecil menuju lautan untuk memulai pelayaran ke Samudra India dan selajutnya meneruskan pelayaran ke daerah lain termasuk Indonesia (Sanyal dalam Adnyana, 2020). Pelaut-pelaut Kerajaan Kalingga Odisha menggunakan Danau 
ini sebagai pelabuhan sebelum menjelajah ke negara lain. Pelaut pelaut ini bergantung arah angin, tidak langsung menuju Indonesia, tetapi singgah dahulu di Sri Lanka sebagai jalur perdagangan. Dan selajutnya mengarungi Samudra India menuju Swarnadwipa atau Sumatra "Island Of The Gold". Dari sini, perahu perahu dapat berlayar turun ke Selat Malaka ke arah Palembang dan memgambil rute laut ke Borneo dan Vietnam. Alternatif lain, mereka bisa melalui jalur Pantai Barat Sumatra menuju Bali dan Java (Jawa) atau Yavadwipa (Sanyal dalam Adnyana, 2020). Setelah melakukan perdagangan, dan melalukan hubungan bilateral lainnya, para pelaut india tersebut akan berbalik arah menggunakan arah angin menuju Srilangka dan selanjutnya kembali ke Odhisa India Selatan.

Bukti tertulis dalam prasasti Bali Kuno yang mendukung dan dapat dikaitkan dengan Bali yatra "perjalanan orang India memasuki Bali" terdapat dalam prasasti Sembiran A IV yang menjelaskan terkait berlabuhnya pelaut atau pedagang di Manasa dengan tulisan prasastinya seperti ini. ...mangkana yan hana banyaga, sakeng sabang jong bahitra, cumunduk i manasa.... "...demikianlah, apabila ada saudagar, dari seberang jauh memakai perahu, berlabuh di Manasa...." (Marzuki dalam Adnyana, 2020). Berdasarkan prasasti tersebut dapat diketahui bahwa Bali Utara tepatnya Buleleng pada Desa Sambiran atau Tejakula sebagai pintu masuknya Bali atau tempat pelabuhan pada masa Bali Kuno. Berdasarkan bukti tersebut menunjukkan ada kemungkinan asumsi bahwa budaya India secara intens dapat langsung masuk ke Bali, tanpa melalui pulau Jawa dan ada juga pengaruh dari Jawa secara tidak intens yang sama melalui India (melalui kerajaan Hindu dipulau Jawa). Pengaruh India tersebut berkaitan dengan aspek budaya, keagamaan (tradisi dan ritual keagamaan), dan hubungan bilateral lainnya. Perjalanan Baliyatra yang dilaksanakan oleh orang - orang India Selatan tepatnya didaerah Odisha (kerajaan Kalingga) merupakan penganut pahaman siwaistik (siwaisme) jadi ada kemungkinan orang-orang India Selatan daerah Odish memberikan pengaruh terhadap kebudayaan Jawa Kuno dan Bali Kuno mengenai paham siwaistik dan kesusastraan lainnya di Nusantara pada masa Jawa Kuno yang kebanyakan menganut paham siwaistik. Bila diintepretasikan bahasa dan sastra Sanskerta dibawa bersamaan dengan hubungan bilateral bangsa India ke Nusantara sehingga membentuk sebuah sinkretisme kebudayaan India dan Nusantara.

Perkembangan sinkritisme lain ditemukan dalam proyek besar di Nusantara tepatnya abad ke IX pada masa pemerintahan Raja Dharmawangsa Teguh keturunan dari dinasti Isana di Kerajaan Kediri Jawa Timur. Proyek besar tersebut oleh para pujangga (Agastia, 1994: 2) disebut sebagai mangjawaken byasamata yang bermakna membahasa jawakan ajaran-ajaran Bhagawan Byasa yang berbahasa Sanskerta. Proyek besar mangjawaken byasamata yang dilakukan oleh Kerajaan Kediri pada dapat dinyatakan sebagai salah satu indikator dalam integrasi bahasa Sanskerta kedalam bahasa Jawa Kuno pada masa pemerintahan Raja Dharmawangsa Teguh dan terjadinya sinkritisme ajaran Veda dan ajaran leluhur Nusantara, hal tersebut juga memacu para pujangga Jawa Kuno dalam menghasilkan karya-karya kesusastraan baik yang bersifat kakawin, tutur, tattwa dan sebagainya.

Sinkritisme ajaran Veda dan ajaran leluhur telah terjadi berabad-abad lamanya, baik dari 5 teori masuknya agama Hindu ke Indonesia, dari proses perjalanan orang India 
ke Nusantara yang dikenal dengan Bali Yatra, serta dari proses mangjawaken byasa mata yang dilakukan oleh raja Kediri yaitu Dharma Wangsa Teguh pada abad ke-IX masehi. Sebagaimana evolusi Hindu yang terjadi di India (baca: Phalgunadi, 2010) maka di Nusantara evolusi ajaran Veda dan ajaran leluhur telah merubah wajah dan kharakteristik Hindu yang sesuai dengan kearifan lokal Nusantara. Runtuhnya majapahit mengantarkan seluruh ajaran ke pulau Bali dan berkembang di Bali, sehingga di Bali mengalami suatu proses "Jawanisasi" yang sistematis. Orang-orang dari Jawa menetap di Bali sambil membawa ajaran dan praktik keagamaannya. Berbaurnya kedua aliran itu, yakni proses "Jawanisasi" di satu pihak terhadap masyarakat dan kebudayaan Bali melalui kontak dengan kalangan keraton beserta peraturan-peraturan administratifnya, dan meningkatnya proses "Balinisasi" di pihak lain di kalangan keraton-keraton itu sendiri. Suatu ketika keadaan di Jawa semakin berubah dan pengaruh Jawa semakin pudar sampai segala hubungan terputus, sehingga menyebabkan Bali melahirkan keanekaan bentuk kebudayaan yang meriah (Zoetmulder dalam Erawati, 2015). Perpaduan itu telah merubah kharakter Hindu di Bali dengan banyaknya proses filterisasi hingga diwarisi hingga saat ini.

\subsection{Jas Merah Perjuangan Agama Hindu di Indonesia}

Agama Hindu sebagai agama tertua di dunia, namun sistem ketatanegaraan Republik Indonesia baru mencatat Hindu sebagai agama yang resmi diakui keberadaannya di Indonesia yang sejajar dengan agama Islam, Kristen, Katolik dan Budha diawali dengan Keputusan Menteri Agama RI No. 40 Tahun 1960 dan No 100 Tahun 1962 selanjutnya diterbitkannya KEPRES No. 1 Tahun 1965 yang dikeluarkan oleh pemerintahan Presiden Soekarno (55 Tahun jika dihitung ke tahun 2020) kemudian dituangkan dalam UU No. 5 tahun 1969 (Ismail, 2016:3).

Jika dipahami jas merah perjuangan leluhur terdahulu sehingga Hindu diakui sebagai "agama", namun, untuk menuju ke sana, banyak jalannya berliku yang harus dilewati dan diperjuangkan baik secara adminitrasi konstitusional maupun perumusan, penyamaan persepsi, dan lain sebagainya sehingga Hindu dan ajarannya kini terwarisi pada kita selaku generasi muda. Mengutip dialog singkat tokoh Hindu dengan Menteri Agama RI yang dikutip dari tulisan (alm) bapak I Gusti Bagus Sugriwa yang sebagaimana disampaikan kepada Ida Bagus Agastya (1973:1-15).

Diawali pada tanggal 26 Desember 1950 Menteri Agama yang bernama K.H Masykur bersama sekjen datang ke kantor daerah provinsi Bali. Berdialog dengan I Gusti Bagus Sugriwa

Menteri Agama : "yang saya ketahui nama agama saudara-saudara ada bermacam-macam yaitu, agama bali, agama tirtha, agama hindu bali, agama siwa Buddha manakah yang benar?

IGBSugriwa : : Hindu Bali yang tepat!

Menteri Agama : saya ingin mendapatkan penjelasan tentang agama hindu. Menurut pengetahuan saya agama Hindu itu banyak Dewadewa misalnya Dewa Brahma, Wisnuu, Siwa, dl. Terhitung polytheisme, berdewa banyak. Karena itu tidak dapat 
disesuaikan dengan pancasila dasar Negara kita yang berketuhanan yang maha esa.

IGB Sugriwa : itu benar, tetapi agama kami warisan dari agama purba Indonesia Purba yang bertuhankan Sang Hyang Tunggal yang disebut Sang Hyang Widhi, Sang Hyang Wenang, dls. Yaitu monotheisme bertuhankan Esa. Upakaranya diperlengkapi dengan babali (sasajen) disebut agama Bali.

Menteri Agama : kenapa di pamarajan banyak ada bangunan-bangunan tempat menyembah Dewa-Dewa? Saya pernah bertanya kepada seorang pedanda, beliau mengiyakan menyembah dewadewa banyak.

IGB Sugriwa : bangunan-banguna yang ada di pamarajan itu adalah tempat berbakti (bukan menyembah) kepada bhatara-bhatari roh suci leluhur kami. Kalau sembahyang kepada Tuhan dibuatkan bangunan darurat dinamai; sanggar surya atau sanggar agung, duhuring akasa, padmasana. Ajaran Indonesia Purba setelah menyembah kepada Tuhan Yang Maha Esa, berbakti pula kepada roh suci leluhur yang diseut nenek moyang.

Menteri Agama : tentang sembahyang itu apakah tiap-tiap hari keliwon atau purnama tilem?

IGB Sugriwa : tiap-tiap hari ketiga kali yang dinamai Tri Sandhya kala, termasuk juga keliwon dan purnama tilem.

Menteri Agama : bagaimana soal hindunya yang menjadi Hindu Bali?

IGB Sugriwa : pengertian Hindu di sini adalah Siwa Buddha, Hindu Sekte Siwa dan Buddha sekte Mahayana, berpadu (syncitisme) dengan agama Bali. Sebab itu ada dalam kenyataan pendeta siwa, pendeta Buddha, dan pendeta-pendeta Bali yang sangat banyak. Misalnya pemangku kahyangan, empu dukuh, dll.

Menteri Agama : Kalau begitu, bisa diterima, tetapi nantikan dulu sampai saya keliling di Sunda Kecil !...

Dua tahun dalam penantian dan harapan setelah dialog panjang itu tepatnya tanggal 10 Oktober 1952 datang kembali Menteri Agama RI (K.H. Masjkur) memberikan ceramah di Balai Masyarakat Denpasar yang isinya tidak dapat mengakui dengan agama Hindu Bali, karena tidak ada peraturan untukitu berbeda dengan agama Islam dan agama Kristen memang telah ada peraturannya.Mendengar hal tersebut, organisasi-organisasi agama yang telah ada di Bali, misalnya paruman para pendeta, panti agama Hindu, dll, mengadakan pertemuan di Tampak Siring menetapkan nama agama kita Hindu Bali. Karena ceramah 10 Oktober 1952 itu maka semua organisasi agama di Bali menjadi kecewa, lalu mengadakan surat-surat perjuangan kepusat dibantu DPRD Bali.

Pertengahan tahun 1953 pemerintah daerah Bali membentuk Jawatan Agama Otonom Daerah Bali bertujuan untuk mengatur pelaksanaan agama umat Hindu Bali, karena belum diatur dari pusat. Perjuangan organisasiorganisasi agama di Bali terus berjuang dan memperjuangkan agama Hindu Bali dengan penuh lika-liku. Pada tahun 1958 suatu Delegasi yang terdiri dari wakil- 
wakil organisasi agama yaitu. Ida Pedanda Made Kemenuh, Ketut Kandia, I Gusti Pt Merta, I Gusti Ananda Kesuma D.1l. Menghadap Presiden Soekarno di tampak siring. Dengan agenda audiensi dan memohon kepada Presiden RI Bung Karno agar dapat mengakui dengan resmi agama Hindu di Bali.

Akhir Audiensi tersebut bapak Presiden RI Soekarno berjanji akan menolong berbicara kepada Menteri Agama RI. dan akhirnya tahun 1958 keluar surat keputusan Menteri Agama RI, dan mulai tanggal 2 Januari 1959 di Kementerian Agama RI di adakan Biro Urusan Agama Hindu di kepalai oleh I Gst Gede Raka dibantu oleh Pak Nyoman Kadjeng dan I Gst Oka Diputra. Hingga pada akhirnya banyak masukan dari berbagai tokoh di Nusantara untuk bisa mengakomodir kepercayaan lainnya yang hampir sama esensinya dan hanya beda kemasannya saja, maka Hindu Bali berubah menjadi Hindu untuk memberikan ruang kepada kepercayaan lainnya yang hampir sama dengan Hindu Bali (seperti Dayak Kaharingan, Sunda Wiwitan, Hindu Aluk'todolo, Hindu Tolotang, Hindu Perbegu, Hindu Key, Hindu Suku Buru, Hindu wayah Kaki, Hindu Tengger, Hindu Jawa, Hindu Selayar, Hindu di Kampung Madura, Hindu di Sumba dsbnya). Maka melalui KEPRES No. 1 Tahun 1965 yang dikeluarkan oleh pemerintahan Presiden Soekarno, Hindu masuk kedalam tatanegaraan Indonesia dituangkan dalam UU No. 5 tahun 1969. Periode 19661980, dan pada saatu itu banyak orang dan masyarakat pada Tengger di kawasan Bromo, Jawa Timur; orang Bugis To Wani To Lotang, Toraja-Mamasa, Toraja Sa'dan di Sulawesi Selatan; sebagian orang Karo di Sumatera Utara; dan orang Ngaju dan Luangan di Kalimantan Selatan menyatakan diri mereka sebagai Hindu, dstnya.

\subsection{Perumusan Konsep Keberagamaan Hindu dalam Kehidupan Berbangsa dan Bernegara}

Pengakuan Hindu di Indonesia memberi semangat para intelektual Hindu pada masa itu untuk segera merumuskan konsep keberagamaan Hindu bagi kehidupan berbangsa dan bernegara. Dimulai entitas tertinggi yang awalnya dinyatakan Sang Hyang Tunggal diganti dengan dengan Sang Hyang Widhi Wasa. Nama ini popular oleh gerakan reformis agama pada masa itu, nama ini merupakan refresentasi kuno tatanan kosmis dalam Jawa Kuno. Kata Sang Hyang mengacu konteks ketuhanan, dengan istilah Vidhi dari bahasa Sanskerta berarti takdir, aturan, status, hukum, ritus dan juga pencipta, dan kata Wasa berarti kehendak, keinginan, kuasa, dan kekuatan, sehingga Sang Hyang Widhi Wasa dapat diterjemahkan Sang Penguasa Kekuatan Takdir (Gonda, 1975:23). Lebih lanjut Gonda (1975:23) menyatakan ..in modern Bali Vidhi (Viddhi) - the Indian designation of rule, destiny' which also applied to some individual gods-denotes that principle which, representing the unity if the universe, is beyond all plurality and act as the guardian of the cosmic and moral order "di Bali modern, Vidhi (Viddhi)-sebutan dalam bahasa India untuk "aturan, takdir" yang juga digunakan untuk menyebut beberapa individu dewa-berarti prinsip yang karena mewakili kesatuan alam semesta, melampaui segala kemajemukan dan bertindak sebagai tatanan kosmis dan moral". Dilanjutkan dengan kitab suci agama Hindu didefinisikan adalah Veda terbagi atas Veda Sruti, Veda Smerti dan Yajna. Tokoh 
intelektual Hindu Ida Bagus Mantra, Ida Bagus Oka Punyatmadja, dan Tjokorda Rai Sudharta yang menempa diri di India membuat rencana untuk membentuk dewan hinduisme dengan tujuan menyatukan dan melembagakan ajaran agama Hindu. Sehingga terbentuknya nama Parisada Hindu Dharma Bali yang kemudian berubah menjadi Parisadha Hindu Dharma. Dan mulainya disusun Tri Sandhya sebagai kumpulan mantra Sanskerta dalam aktivitas doa seharihari.

Tri Sandhya "tiga pertemuan waktu" sebagai doa hindu yang dilakukan setiap hari dengan formulasi pagi, siang dan sore hari. Disusun Bait pertama gayatri berasal dari mantram $R g$ Veda dan Yajur Veda (yang di Bali terdapat pustaka Weda Parikrama), bait kedua dikutip dari Narayana upanisad, bait ketiga dikutip dari Siwa purana, bait ke 4-5-6 dikutip dari Veda Peganggan (Mantram Suci dari Sulinggih Bali). Matram bait pertama Tri Sandhya pada berisi pujaan dan pujian, mantram bait kedua dan ketiga berisi pengakuan kepada manifestasi Ida Sang Hyang Widhi Wasa dalam banyak wujud, mantram bait keempat pernyataan sebagai manusia penuh akan dosa, mantram ke lima berisi permohonan maaf secara umum dan menyeluruh, serta mantram ke enam berisi pemohonan maaf secara khusus pada diri (Surada, 2014). Kemudian disusunnya lima pasal iman dalam Hindu yang dikenal dengan Panca Sraddha disusun oleh Ida Bagus Oka Punyaatmadja, yang kemudian didorong oleh Ida Bagus Mantra sebagai dasar teologis Hindu. Selanjutnya Upadesa disusun oleh Tjokorda Rai Sudharta dengan tim (I Gusti Bagus Sugriwa, Ida Bagus Agastya, Gde Sura, dll) sebagai publikasi pertama yang menyajikan pelajaran agama Hindu secara sistematis. Pelajaran ini disajikan dalam bentuk dialogi antara Sang Guru Dharmakirti dan muridnya Sang Suyasa yang jelas terinspirasi dari komposisi pustaka upanisad, yang mengambil kerangka dasar dalam tiga bidang tattwa susila, dan acara yang premis yang diungkap oleh Goris di Campuan (Picard, 2020).

Didalam isi teks upadesa bahwa Sang Hyang Widhi Wasa juga muncul dalam tiga fungsi (Tri Murti dan Tri Sakti) penciptaan (Brahma) dengan sakti Dewi Saraswati, Pelestarian (Wisnu) dengan sakti Dewi Sri, dan Pelebur (Siwa) dengan sakti Dewi Uma, ketiga fungsi ini menjadi tiga tempat suci yaitu khayangan tiga, pura Desa untuk memuja Brahma, pura Puseh untuk memuja Wisnu, dan pura Dalem untuk memuja Siwa. Lalu etika diringkas dengan rumusan Tat Twan Asi diambil dari Chandogya Upanisad. Acaranya didorong oleh Tri Rna (tiga hutang) yang wajib dibayar oleh setiap orang Hindu lahir, kepada Tuhan, kepada Leluhur, dan kepada orang bijak, kemudian ini dikenal dengan Panca Yajna. Terdiri atas Dewa Yajna, Pitra Yajna, Rsi Yajna, Manusia Yajna dan Bhuta Yajna.

Berganti era kepemimpinan Presiden RI ke Soeharto, perkembangan konsep keberagamaan Hindu terkontruksi dalam harmoni dan dan toleransi masyarakat Bali melahirkan Tri Hita Karana (Tiga Penyebab Kebahagiaan) yang meliputi hubungan manusia dengan Tuhan (Parhyangan), dengan sesama manusia (pawongan), dan dengan alam (palemahan). Semboyan ini dirumuskan pada November 1966 oleh Kapten I Wayan Mertha Sutedja pada konferensi di Denpasar untuk memperkuat posisi umat Hindu Bali dalam suatu konfigurasi politik baru dan telah disajikan sejak saat itu sebagai filsafat tradisional orang 
Bali yang berasaskan kitab-kitab Veda (Wirawan, 2011). Dilanjutkan dengan ditetapkan oleh Parisada golongan pendeta terdiri atas pandita dan pinandita. Pandita adalah orang yang telah terlahir dalam proses dwijati dan pinandita adalah orang yang mengalami proses eka jati. Lalu parisada mempopulerkan istilah desa, kala, patra berkaitan dengan aspek agama, adat dan budaya yang berbeda-beda di setiap wilayah.

Parisada mengajukan usulan ke pemerintah RI agar hari raya keagamaan Hindu dapat dijadikan libur nasional seperti nyepi, siwaratri, pagerwesi, galungan kuningan, saraswati sebagai hari libur nasional, agar ada kesamaan dengan agama lainnya, namun nyatanya yang diakui libur nasional adalah hari raya nyepi semenjak tahun 1983 (Picard, 2020). Selanjutnya dirumuskan upacara suddhi wadani yang merupakan upacara peralihan orang yang ingin kembali memeluk agama Hindu, upacara suddhi wadani konsep yang dicetuskan abad ke XIX oleh Arya Samaj (Titib 1991). Bertahun kemudian dibutuhkan organisasi masa pemuda Hindu untuk melawan tekanan dari organisasi agama lainnya semakin kuat dikampus-kampus. Maka pada maret 1984 atas prakarsa mahasiswa Bali di Universitas Gadjah Mada di Yogyakarta terbentuk perhimpunan pemuda Hindu Indonesia atau yang dikenal dengan Peradah untuk menggantikan AMHI yang kegiatannya telah berhenti selama tahun 1970an (Picard, 2020).

Dimulai tersusunnya konsep Dharma Wacana, Dharma Gita, Dharma Tula, Dharma Yatra, Dharma Sadhana, Dharma Santi, dan dimulainya penerbitan pustaka-pustaka bagi umat Hindu meliputi Pustaka Veda, Kramaning Sembah (meliputi Puja Tri Sandhya, dan Panca Sembah). Parisada selaku lembaga Agama Hindu mulai memetakan wilayah nasional dengan membangun serangkaian pura. Tahun 1992 berdirinya Pura Mandara Giri Semeru Agung sebagai pura khayangan Jagat dan dilanjutkan dengan Pembangunan Pura Agung Jagatnatha di setiap ibu kota kabupaten di Bali dan juga dibeberapa ibu kota provinsi di luar Bali. dilanjutkan tranformasi tri sadhaka menjadi sarwa sadhaka. Terkonsepnya salam umat Hindu Indonesia yaitu dengan mengucapkan Om Swastyastu "Ya Tuhan Semoga Ia Selamat". Dilanjutkan pengkonsepan tarian Bali kedalam tiga klasifikasi yaitu 1) Seni Tari Wali, 2) Seni Tari Bebali, 3) Seni Tari Bebalih-balihan dengan tujuan agar dapat membedakan praktik tari keagamaan, adat, dan hiburan untuk masyarakat umum pada pariwisata budaya. Oleh karena itu, dapat dipahami dalam perkembangan setelah perumusan konsep keberagamaan Hindu bagi kehidupan berbangsa dan bernegara, ajaran Hindu tidak terpakukaku pada kalimat-kalimat Veda, lontar, namun jiwa atau esensinya Veda dengan keyakinan lokal.

Seni Budaya, tradisi atau adat menjadi media penampilan ajaran Hindu di Indonesia sehingga memahami historis dari jas merah Agama Hindu di Indonesia dapat dipahami ajaran agama Hindu kaya akan nilai religious, filosofis, serta ajaran yang awalnya berasal dari India telah berevolusi di Nusantara (sebagaimana sinkritisme pada kasus mangjawaken byasa mata), terkhususnya di pulau Dewata Bali. agama Hindu di Indonesia berkembang, terbuka dan berkelanjutan menghadapi perubahan-perubahan jaman. Seperti perjuangan para intelektual dulu agar Hindu diakui di Indonesia, maka esensi 
Hindu di Nusantara adalah mengedepankan kearifan lokal Nusantara dengan dijiwai oleh ajaran Hindu dan Pustaka Suci Veda.

\section{PENUTUP}

Para intelektual Hindu dan rohaniawan Hindu pasa masa itu, berjuang untuk mendapatkan pengakuan dari Negara Indonesia. Pengakuan agama Hindu diawali dari gagasan intelektual Hindu di pulau Bali dengan penuh likaliku, suka duka perjuangan leluhur dahulu hingga Hindu di akui sebagai agama di Indonesia. Sinkritisme ajaran Veda dan ajaran leluhur telah terjadi berabad-abad lamanya, baik dari 5 teori masuknya agama Hindu ke Indonesia, dari proses perjalanan orang India ke Nusantara yang dikenal dengan Bali Yatra, serta dari proses mangjawaken byasa mata yang dilakukan oleh raja Kediri yaitu Dharma Wangsa Teguh pada abad keIX masehi.

Seni Budaya, tradisi atau adat menjadi media penampilan ajaran Hindu di Indonesia sehingga memahami historis dari jas merah Agama Hindu di Indonesia dapat dipahami ajaran agama Hindu kaya akan nilai religious, filosofis, serta ajaran yang awalnya berasal dari India telah berevolusi di Nusantara (sebagaimana sinkritisme pada kasus mangjawaken byasa mata), terkhususnya di pulau Dewata Bali. agama Hindu di Indonesia berkembang, terbuka dan berkelanjutan menghadapi perubahan-perubahan jaman. Seperti perjuangan para intelektual dulu agar Hindu diakui di Indonesia, maka esensi Hindu di Nusantara adalah mengedepankan kearifan lokal Nusantara dengan dijiwai oleh ajaran Hindu dan Pustaka Suci Veda.

\section{DAFTAR PUSTAKA}

Adnyana, Putu Eka Sura. 2020. Integrasi Bahasa Sanskerta dalam Bahasa Jawa Kuno Pada Lontar Bhuana Kosa. Tesis Magister Ilmu Linguistik. Denpasar: Pascasarjana Universitas Udayana (UNUD).

Adnyana, Putu Eka Sura. 2020. Karya Prof. Phalgunadi “Sekilas Sejarah Evolusi Agama Hindu": Menelisik dan Memahaminya dalam Bingkai Filsafat Sejarah Hindu pada Jurnal Sanjiwani: Jurnal Filsafat Volume 11 Nomor 2, September 2020. Denpasar.

Agastia, Ida Bagus Gde. 1994. Kesusastraan Hindu Indonesia, Sebuah Pengantar. Denpasar: Yayasan Dharma Sastra.

Erawati, Ni Ketut Ratna. 2015. Eksistensi dan Dinamika Kosa Kata Bahasa Jawa Kuna Pada Masyarakat Bali Masa Kini dalam Jurnal Kajian Bali Volume 05, Nomor 01, April 2015. Denpasar.

Gonda. 1975. "The Indian Religion in Pre Islamic Indonesia and their survival in Bali" dalam Hanbuch der orientalistik, Part 3: Indonesian, Malaysia und die Philippinen, Leinden/Koln. E.J. Brill. Hal 1-54.

Ismail, Nawari. 2016. Perubahan Sosial-Budaya Komunitas: Agama Dam. Yogyakarta: CV Budi Utama.

Maswinara, I Wayan. 2009. Rg Veda Samhita Sakala Sakha Mandala I, II, III. Surabaya: Paramitha Surabaya. 
Phalgunadi, I Gusti Putu. 2010. Sekilas Sejarah Evolusi Hindu. Denpasar: Widya Dharma

Picard. 2020. Kebalian: Kontruksi Dialogis Identitas Bali. Jakarta: Kepustakaan Populer Gramedia.

Pudja. Gde. 1979. Rg Veda Mandala I. Jakarta: Departemen Agama RI

Riwayat Hidup I Gusti Bagus Sugriwa 1973, sebagaimana disampaikan kepada Ida Bagus Gede Agastia di Denpasar.

Surada, I Made. 2014. Tri Sandhya dalam penataran dan pembinaan pemangku "rohaniawan Hindu". Denpasar: Makalah

Titib, I Made. 1991. Pedoman Upacara Suddhi Wadani. Denpasar: Upada Sastra.

Wirawan. I Made Adi. 2011. Tri Hita Karana: Kajian Teologi, Sosiologi, dan Ekologi Menurut Veda. Surabaya: Paramitha. 